\title{
Hypertension Self-Management Support in Primary Care: A Quality Improvement Study
}

\author{
By Jean Ann Davison* \\ Marva M. Price \\ Debra J. Barksdale \\ Katrina E. Donahue
}

\begin{abstract}
This nurse practitioner-led quality improvement (QI) study was designed to improve clinical performance in hypertension (HTN) management that focused on selfmanagement support (SMS) among adult patients at a primary care clinic with a high rate of cardiovascular disease. The design included retrospective baseline of meaningful use population data $(N=1,210)$ generated six months prior to study start date and an analysis of the data during the six-month QI study $(N=1,409)$. Interventions included staff QI training along with patient education and lifestyle goal setting for SMS of HTN. Electronic medical record data included blood pressure, cholesterol, tobacco use, body mass index, and self-management goals. The primary objective, $>80 \%$ of adults would have documented self-management goals, was achieved and significantly improved from baseline. Nurse practitioners have an important role in meeting the current demand for HTN management in primary care and supporting patients in self-management.
\end{abstract}

Keywords: Cardiovascular disease, Hypertension, Primary care, Quality improvement, Self-management support

\section{Introduction}

Cardiovascular disease (CVD) causes one in three deaths in the United States (US) and is the most common adult diagnosis seen in primary care (Centers for Disease Control and Prevention 2011, James et al. 2014). The American Heart Association (AHA) projects that by 2030, 40.5\% of the US population will have some form of CVD, with an estimated cost to the national health care system of $\$ 1$ trillion per year (Tomaselli et al. 2011). The US Department of Health and Human Services (HHS) launched the national Million Hearts initiative in 2011. The goal was to prevent 1 million heart attacks and strokes in 5 years with strategies directed at the leading modifiable risks for CVD (US Department of Health and Human Services 2011). The focus of this campaign is to empower Americans to make healthy lifestyle choices for global CVD risk reduction and to improve outcome goals in the $A B C S$ : $\mathrm{A}=$ Aspirin therapy for people at risk, $\mathrm{B}=\mathrm{Blood}$ pressure control,

\footnotetext{
* Clinical Assistant Professor, School of Nursing, University of North Carolina at Chapel Hill, USA.

${ }^{\dagger}$ School of Nursing, University of North Carolina at Chapel Hill, USA.

* School of Nursing, University of North Carolina at Chapel Hill, USA.

${ }^{\circ}$ School of Medicine, University of North Carolina at Chapel Hill, USA.
} 
$\mathrm{C}=$ Cholesterol control, $\mathrm{S}=$ Smoking cessation and sodium reduction (Tomaselli et al. 2011).

Hypertension (HTN) is the single most independent and modifiable risk factor for CVD, stroke, congestive heart failure, and chronic renal disease (US Department of Health and Human Services 2011). Approximately $31 \%$ of US adults have HTN, with studies suggesting that a $10 \%$ increase in treatment of HTN could prevent 14,000 premature deaths each year among adults less than 80 years of age (Centers for Disease Control and Prevention 2011). The goal of the Million Hearts campaign is that $65 \%$ of the US population will have a BP $<140 / 90 \mathrm{mmHg}$ by 2017 while currently only 52\% (Ritchey et al. 2014) of the US population has BP controlled to $<140 / 90 \mathrm{mmHg}$ (US Department of Health and Human Services 2011).

\section{Background and Significance}

Evidence-based interventions typically follow the clinical practice guidelines on HTN set forth by the Joint National Committee on Prevention, Detection, Evaluation and Treatment of High Blood Pressure, JNC 7 (20032013) and most recently updated in 2014 per JNC 8 (US Department of Health and Human Services 2011, James et al. 2014). The evidence supports assessment of patients for CVD risks in personal, family, and social history, along with team-based management of modifiable risk factors including obesity, physical inactivity, unhealthy diet, uncontrolled diabetes, dyslipidemia, tobacco, alcohol, substance abuse, stress, and depression (Artinian et al. 2010, Chobanian et al. 2003, Community Preventive Services Task Force 2012, Eckel et al. 2013).

Because HTN can be asymptomatic, detecting and controlling it continues to be a challenge. The JNC 7 report recommended lifestyle modifications, and the American Heart Association (AHA) recommends strongly individual goal setting and community group-based interventions to achieve healthy lifestyle changes (Artinian et al. 2010, Chobanian et al. 2003, Eckel et al. 2014). A lowsodium diet (guided by the Dietary Approaches to Stop Hypertension also known as the DASH diet) was shown to reduce systolic blood pressure (SBP) by $8-14 \mathrm{mmHg}$, and a 10-kilogram weight loss can reduce SBP by $5-20$ $\mathrm{mmHg}$. Similarly, 30 minutes of aerobic physical activity most days of the week can result in a 4-9 $\mathrm{mmHg}$ SBP reduction, and limiting alcohol consumption can reduce SBP by $2-4 \mathrm{mmHg}$ (Chobanian et al. 2003). Changes in lifestyle behaviors and the related biomedical CVD risk factors have been achieved across all cultural groups in clinical and community interventions that have used a broad, multimedia-communication approach (Ritchey et al. 2014).

Nurse practitioners (NP) have an important role in meeting the current demand for HTN prevention and management in primary care (Wright et al. 2011). Clark and colleagues conducted a systematic review of nurse-led interventions that addressed patient lifestyle modifications. Their review reported significant decreases in BP in primary care patients as compared to 
those under usual clinical medical care, especially in African American patients (Clark et al. 2010). Although the absolute differences in BP were small, the authors noted that with just a $3 \mathrm{mmHg}$ reduction in SBP, the risk of stroke, coronary heart disease, major cardiovascular events, and cardiovascular death were decreased by 20-30\% (Clark et al. 2010, Neal et al. 2000).

This paper describes a nurse practitioner-led quality improvement (QI) intervention to improve clinical performance in the practice of HTN management with a focus on self-management support (SMS) among adult patients at a rural primary care clinic with a high rate of CVD. The Agency for Healthcare Research and Quality has favorably evaluated many studies and quality improvement projects on patient SMS programs in primary care that focus on diabetes, asthma, and other chronic conditions, but few are on SMS for HTN management (Agency for Healthcare Research and Quality 2012, Battersby et al. 2010).

\section{Quality Improvement Project to Improve Self-Management of Hypertension}

The goal of this quality improvement (QI) project was to evaluate and improve HTN self-management support (SMS) for CVD risk reduction using the JNC 7 guidelines, a team-based approach, and the Chronic Care Model $(\mathrm{CCM})$ as a framework in the primary care clinical setting described below. The CCM identifies six areas that interact in the team management of chronic care and are applicable to systematic, client/patient-centered, evidence-based care (Battersby et al. 2010). These six areas are labeled self-management support, decision support, delivery system design, clinical information system, organization of health system and linkages to the community for effective use of community resources to provide informed and empowered client/patient centered care and improve outcomes (Table 1). A central feature of this model is SMS, which features two components identified as collaborative partnership with the patient and health care team and self-management education. The $\mathrm{CCM}$ has been shown to be effective in guiding clinical quality initiatives in CVD, and SMS increases patient self-efficacy to improve clinical outcomes (Coleman et al. 2009).

The goal of any QI initiative is to develop a planned, systematic, and collaborative approach to designing, measuring, assessing, and improving performance. The steps in a QI process and program evaluation include engaging the stakeholders, forming a QI team, and identifying champions. In this QI, planning meetings were led by the NP and took place with the practice owner, providers, health care staff, and community health care leaders. The clinical question guiding the project was whether a population of adults with a diagnosis of primary HTN who receive care at a primary care practice in rural NC would show improvement in their BP self-management and goal setting after an NP-led implementation of the CCM and JNC 7 guidelines with an emphasis on SMS. The objective of this six-month QI initiative (September 15, 
2011-March 14,2012 ) was to have $80 \%$ or more patients actively setting goals in collaboration with their providers, as demonstrated by chart review. The modifiable risk factors and baseline meaningful use measures related to HTN and CVD risk: BP, LDL cholesterol, tobacco use and Body Mass Index (BMI) were measured six months before the QI intervention (March 15-September 14, 2011) and during the QI intervention (September 15, 2011-March 14, 2012).

Table 1. The Six Areas of the Chronic Care Model Used with the Aims for this QI Study

\begin{tabular}{|l|l|}
\hline $\begin{array}{l}\text { Organization of } \\
\text { Health Care }\end{array}$ & $\begin{array}{l}\text { Leadership and organization identify self-management goal } \\
\text { setting as important to chronic care management and provide } \\
\text { resources for it. }\end{array}$ \\
\hline $\begin{array}{l}\text { Clinical Informa- } \\
\text { tion System }\end{array}$ & $\begin{array}{l}\text { Correct data entry into EMR system and updated EMR to allow } \\
\text { for goal setting meaningful use measures. }\end{array}$ \\
\hline Decision Support & $\begin{array}{l}\text { Increased provider and staff knowledge and fidelity to the JNC } \\
7 / 8 \text { updated evidence based guidelines. }\end{array}$ \\
\hline $\begin{array}{l}\text { Delivery System } \\
\text { Design }\end{array}$ & $\begin{array}{l}\text { Identified and expanded roles of staff in patient care for an } \\
\text { effective and efficient system design. }\end{array}$ \\
\hline $\begin{array}{l}\text { Self-management } \\
\text { Support }\end{array}$ & $\begin{array}{l}\text { Improve patient self-management of healthy behaviors and self- } \\
\text { efficacy to optimize health outcomes. }\end{array}$ \\
\hline $\begin{array}{l}\text { Community } \\
\text { Support }\end{array}$ & $\begin{array}{l}\text { Work closely with community, state and national programs to } \\
\text { support patient's in CVD educational, nutritional, fitness } \\
\text { programs and smoking cessation }\end{array}$ \\
\hline
\end{tabular}

\section{Community Assessment}

In the rural county in North Carolina, US, where this project was conducted in 2011-12, patients had an exceptionally high rate of CVD. Heart disease was the leading cause of death, and strokes were the third leading cause of death (NC State Center for Health Statistics 2011). Many of the risk factors associated with a high incidence of CVD were apparent in the profile of this county's population in 2011-12, including race, gender, age, and income disparities. It was a small county (population) with 39,464 residents and a percapita personal income of $\$ 21,775$. The median age (41.4 years) was older than the state as a whole (37.4 years), all of which are factors implicated in the incidence of CVD (Centers for Disease Control and Prevention 2011). The population was $68.3 \%$ white, $27 \%$ African American, 4\% Latino, and $0.7 \%$ American Indian (US Bureau of the Census 2011). There were also gender and racial disparities in CVD: Heart disease rates were higher for adult males (294 events per 100,000) than females (175.9), and overall 12.3\% higher for African American males (NC State Center for Health Statistics 2011).

According to the 2011 Behavioral Risk Factor Surveillance System, 32\% of 11,515 North Carolina (NC) adults surveyed had been told they have HTN (Centers for Disease Control and Prevention 2012). When using a BP reading of $115 / 75 \mathrm{mmHg}$ as a starting point, CVD risk doubles with each increment of 
20/10 $\mathrm{mmHg}$; therefore, managing HTN should decrease morbidity and mortality associated with HTN in this community (Chobanian et al. 2003).

\section{Method}

\section{Setting and Population}

The setting was a primary care office in rural NC. This practice is a Level 3 Patient Centered Medical Home certified by the National Committee for Quality Assurance (NCQA) that captures meaningful use data for population management using an electronic medical record (EMR). The patient population consisted of adults (aged 18-75 years) with the diagnosis of primary HTN who were seen and managed for this diagnosis. At this site 3,218 age-validated patients were seen in the year 2011, and 1,496 patients ( 1 in 2.15 patients) had the ICD 9 diagnostic code of essential HTN. Insurance coverage included Medicare (33\%), Medicaid (13\%), self-pay (3.5\%), and private insurance $(50.5 \%)$. Patient race/ethnicity classifications were: Caucasian (45\%), African American (13\%), undetermined (41\%), and other (1\%). This QI study was approved by the institutional review board of Duke University Medical Center in Durham, North Carolina.

\section{QI Implementation}

\section{$\underline{\text { Staff Interventions }}$}

The core QI improvement team consisted of one NP, one physician, four physician assistants (PAs), a registered nurse (RN), six certified nursing and medical assistants (CNAs/CMAs), front desk/referral staff and community health educators. Team roles were identified and expanded for patient care and education. During the QI project, monthly staff meetings were held with training that focused on evidence-based guidelines for assessment, evaluation, and management of HTN SMS. Meetings and training of staff included topics such as the burden of CVD, the Million Hearts initiative, HTN education and assessment, health literacy, and "teach-back" methods on goal setting. All front desk and clinical staff completed an educational program on the DASH diet, reading food labels, and community resources. Each topic was intended to foster a proactive practice team approach. With the NP as the facilitator, the team made suggestions for improving practice performance by collectively analyzing practice standards during monthly QI meetings. Process changes included developing correct procedures for BP, pulse, and weight/BMI measurements with the CNAs/CMAs measuring BP at the end of the vital signs after the patients had been seated at rest for five minutes or more. An effective and efficient system change in patient/chart flow also was designed during QI meetings, allowing for screening health literacy and starting the conversation about hypertension management during the initial check in with goal setting at the end of the visit. 


\section{$\underline{\text { Patient Education }}$}

All adult patients with a diagnosis of HTN or an elevated BP measurement at their office visit were offered two evidence-based brochures in English or Spanish; Starting the Conversation on Blood Pressure by the NC Prevention Partners and Start with Your Heart Prescription for Better Health from the NC Department of Health and Human Services (NC Department of Health and Human Services 2011, NC Prevention Partners 2011). These educational tools were used to increase patients' understanding of BP and to augment SMS. Starting the Conversation brochures and Start with Your Heart prescription pads included an action plan to set goals in collaboration with the clinic's health care providers for weight loss, physical activity, healthy eating with sodium restriction, tobacco cessation, limiting alcohol use, and improving medication adherence. Triage staff gave the HTN brochures at check-in to all patients with elevated BP and/or diagnosis of HTN and discussed the content areas with them. Patients were encouraged by all staff to set achievable lifestyle modification goals, and the providers documented patients' selfmanagement goals set in the EMR.

Displays on CVD, patient education brochures, and community resources were available to all patients in the office waiting area. These resources included information on the NC tobacco quit line, Start with Your Heart brochures, the community resource guide, and flyers on local community programs such as Eat Smart, Move More, and Weigh Less, Living Healthy with Chronic Disease, and Give Your Heart a Healthy Beat to inform and empower patients. Public Service Announcements were displayed on healthy eating during the holidays, especially around Thanksgiving and the December holiday celebrations. Additionally the local newspaper published articles on healthy living community programs and just after the New Year holiday, devoted an entire page to CVD health in the community, including an interview of the NP who led the QI project in which she discussed improving HTN in the community (Pentecost 2012). Statewide, in February 2012, the NC JustusWarren Heart Disease and Stroke Prevention Task Force began running a public service announcement about the Million Heart's ABCS.

\section{Patient Input}

A diverse convenient sample of interested patients, composed of three males and seven females ages 30-70 years, (two were African American) participated in a six week class called Living Healthy with Chronic Disease and provided feedback during the QI process (Lorig et al. 2006). This group addressed patients' educational needs regarding HTN, their preferences for culturally appropriate HTN resources, and readiness and barriers to achieving selfmanagement goals. Also, the group informed the QI team about preferences for learning to control their HTN and their preferences for the types of community resources they might use to support their self-management goals. 


\section{Measures and Data Collection}

Six months prior to the project, retrospective baseline data were obtained from the adult patient population who were seen for the diagnosis of essential HTN between March 15, 2011, and September 14, $2011(\mathrm{~N}=1,210)$. These baseline data were then compared to data obtained during the six-month QI project, September 15, 2011-March 14, $2012(\mathrm{~N}=1,409)$. Blood pressure standards and measurement were operationalized using the JNC 7 guidelines (Chobanian et al. 2003). Performance measures on BP, LDL cholesterol, tobacco use and BMI were derived from the Healthcare Effectiveness Data and Information Set (HEDIS), a standardized set of performance measurements developed by the National Committee for Quality Assurance for meaningful use. A benchmark that is set by HEDIS states that $65 \%$ of adults with the diagnosis of HTN should have a BP<140/90 mmHg (Turpin et al. 2003).

To determine if patients' self-management goals were set in collaboration with their provider and documented in the patients' EMR individual plan of care, greater than $20 \%$ of charts from patients whose BP was uncontrolled (>139/89 mmHg) were randomly audited each month (10 EMR charts each month). Before the QI project was initiated, the charts of 60 of 246 patients with BP>139/89 mmHg (24\%) were audited. During the QI project, 60 of 293 charts $(20.5 \%)$ were audited. The monthly random charts audits were selected as follows; every $5^{\text {th }}$ patient seen each month with the dx of HTN and BP $>139 / 89 \mathrm{mmHg}$, who had not been previously selected for audit.

For all patients with the dx of essential HTN seen six months prior to the QI and during the QI study, meaningful use CVD key measurements included the number of patients with:

- BP categories of optimal, high normal, hypertensive $(<130 / 80 \mathrm{mmHg}$, $<140 / 90 \mathrm{mmHg}$, and $<159 / 99 \mathrm{mmHg}$ );

- Cholesterol LDL $<100 \mathrm{mg} / \mathrm{dl}$ and $<130 \mathrm{mg} / \mathrm{dl}$;

- Tobacco use yes/no; if yes, offered tobacco cessation assistance; and

- BMI $\left(\mathrm{kg} / \mathrm{m}^{2}\right)=<18.5$ (under-weight), <25 (normal), >24.9 but <30 (over weight) and $>29.9 \mathrm{~kg} / \mathrm{m}^{2}$ (obese).

\section{Results}

Outcomes Analysis

For all measurements, z-tests for independent proportions were conducted to compare the six months of pre-QI baseline data to the data obtained during the six months of the QI. A two-tailed $p$-value was set at 0.05 for significance, and confidence intervals were obtained.

Self-Management Support

Retrospective EMR chart audits for the patients seen each month during the QI months with a diagnosis of uncontrolled HTN (BP>139/89 mmHg) 
revealed that $83 \%$ had documented self-management goals set in collaboration with their provider (Figure 1). Goals discussed included the DASH diet, aerobic physical activity, weight loss, tobacco cessation, moderate alcohol consumption, stress reduction, medication adherence, home BP monitoring, and, as applicable, blood sugar control. At baseline, only $62 \%$ of patients had documented self-management goals; this increased significantly to $83 \%$ $(\mathrm{p}=0.008)$ during the 6 month QI intervention. Figure 1 shows monthly goalsetting numbers both before and during implementation.

Figure 1. Percentage of Documented Monthly Self-Management Goals Set with Patients with the Diagnosis of Uncontrolled Hypertension $(B P>139 / 89 \mathrm{mmHg})^{a}$

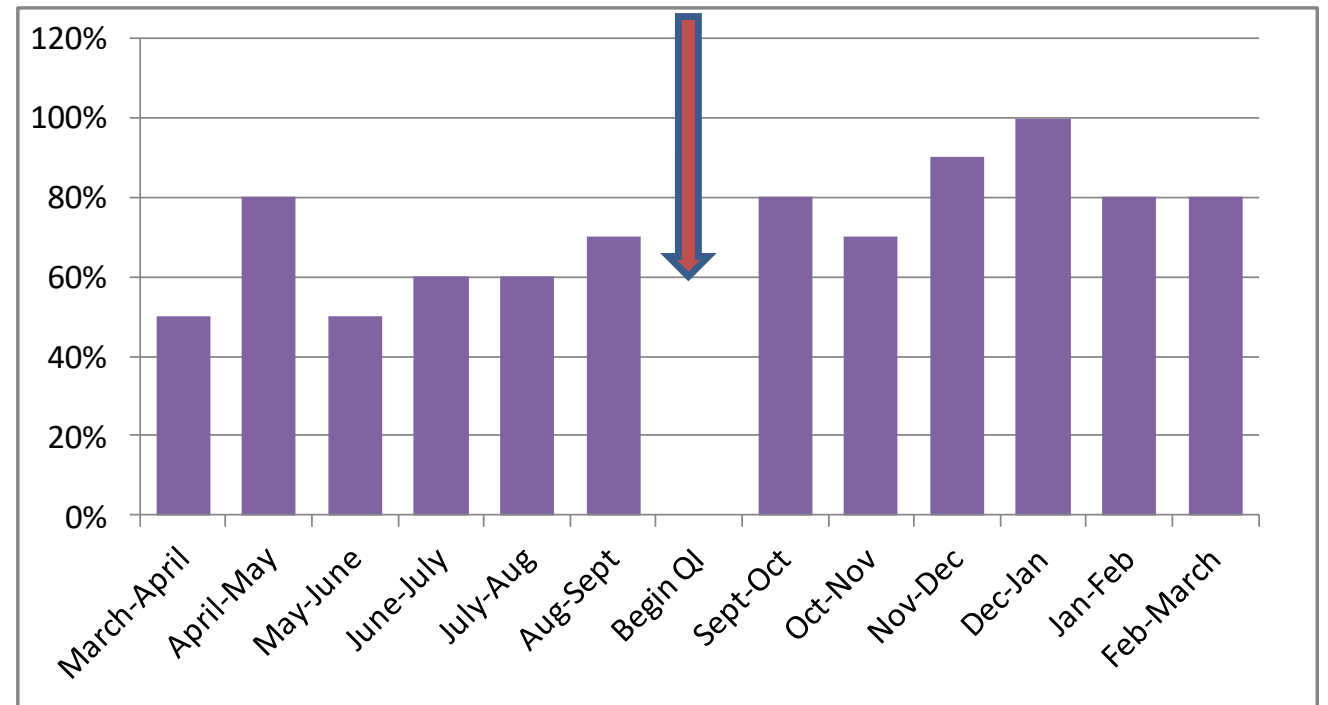

Note: March 15, 2011-September 14, 2011 compared to September 15, 2011-March 14, 2012.

${ }^{\text {a }} \mathrm{N}=120$ (10 charts audited per month) for greater than $20 \%$ of population seen with diagnosis essential hypertension and $\mathrm{BP}>139 / 89 \mathrm{mmHg}$. 
Table 2. Meaningful Use Hypertension Z-test results for Six Months Baseline before Quality Improvement Compared to Six Months during Quality Improvement

\begin{tabular}{|c|c|c|c|c|c|}
\hline $\begin{array}{l}\text { Patients seen } \\
\text { (ages 18-75 years old) }\end{array}$ & $\begin{array}{l}\text { With ICD9 Dx. } 401 \\
\text { Essential HTN }\end{array}$ & $\begin{array}{c}\text { (March 15, 2011-Sept. 14, 2011) } \\
\text { Baseline \% }\end{array}$ & $\begin{array}{c}\text { (Sept 15, 2011-March 14, 2012) } \\
\text { Quality Improve \% }\end{array}$ & Z-value & $\begin{array}{c}\text { Two-tailed } \\
\text { p-value } 0.05\end{array}$ \\
\hline & BP range $^{b}$ & $N=1,210$ & $N=1,409$ & & \\
\hline \multirow{3}{*}{$\begin{array}{l}\text { Last entry blood } \\
\text { pressure (BP) mmHg }\end{array}$} & $\mathrm{BP}<130 / 80$ & 28.93 & 28.67 & 0.14 & 0.88 \\
\hline & $<140 / 90$ & 58.76 & 57.20 & 0.81 & 0.42 \\
\hline & $<160 / 100$ & 87.36 & 87.58 & -0.17 & 0.87 \\
\hline Calculated LDL mg/dL & Last entry $L D L$ & $N=1,051$ & $N=1,168$ & & \\
\hline \multirow{3}{*}{$\begin{array}{l}\text { Low density lipoprotein } \\
\text { cholesterol LDL-C }\end{array}$} & LDL $<100$ & 57.75 & 56.51 & 0.59 & 0.56 \\
\hline & LDL $<130$ & 85.82 & 84.16 & 1.09 & 0.27 \\
\hline & LDL $>129$ & 14.18 & 15.84 & -1.09 & 0.27 \\
\hline $\begin{array}{l}\text { Body mass index (BMI) } \\
\mathrm{Kg} / \mathrm{m}^{2}\end{array}$ & Last entry BMI & $N=1,096$ & $N=1,290$ & & \\
\hline Under weight & $<18.5$ & 0.64 & 0.47 & 0.56 & 0.58 \\
\hline Normal & $<25$ & 11.41 & 11.63 & 0.17 & 0.87 \\
\hline Over weight & $>24.9<30$ & 24.18 & 23.72 & 0.26 & 0.79 \\
\hline Obese & $>29.9$ & 64.96 & 65.27 & -0.16 & 0.87 \\
\hline \multirow{3}{*}{ Documented smoking } & Smoking not blank & $N=1,186$ & $N=1,353$ & & \\
\hline & Current yes & $26.14 \mathrm{~N}=310$ & $25.57 \mathrm{~N}=346$ & 0.33 & 0.74 \\
\hline & Advised to quit & 77.74 & 82.08 & -1.39 & 0.17 \\
\hline
\end{tabular}

Note: $\quad{ }^{\mathrm{a}}$ ICD9 Dx. 401=International Classification of Diseases, 9th Revision and diagnosis code 401 essential hypertension.

${ }^{\mathrm{b}}$ Classification of blood pressure (BP) ranges are based on the Seventh Report of the Joint National Committee on Prevention, Detection, Evaluation, and Treatment of High Blood Pressure. The JNC 7 Report. 
Table 3. QI Results Compared to the US Baseline and Million Hearts Campaign Goals for 2017

\begin{tabular}{|c|c|c|c|}
\hline ABCS prevention measures & $\begin{array}{c}\text { United States } \\
\text { baseline- } \\
\text { population }^{\text {a }}(\%) \\
\end{array}$ & $\begin{array}{c}\text { Quality improvement results } \\
\text { (September 2011-March 2012) } \\
(\%)\end{array}$ & $\begin{array}{c}\text { Million Hearts }^{\mathrm{b}} \\
\text { 5-year population/clinical target goal } \\
2017(\%)\end{array}$ \\
\hline Aspirin for high risk & 47 & 49 & $65 / 70$ \\
\hline Blood pressure $<140 / 90 \mathrm{mmHg}$ & 46 & 57 & $65 / 70$ \\
\hline Management LDL-C ${ }^{c}$ & 33 & 57 LDL-C $<100 \mathrm{mg} / \mathrm{dL}$ & $65 / 70$ \\
\hline $\begin{array}{l}\text { Smoking prevalence } \\
\text { Cessation counseling or meds }\end{array}$ & $\begin{array}{l}20 \\
23\end{array}$ & $\begin{array}{c}26 \text { yes smoke } \\
82 \text { advise/assist }\end{array}$ & $\begin{array}{l}17 /-- \\
65 / 70\end{array}$ \\
\hline Overweight BMI $>24.9 \mathrm{~kg} / \mathrm{m}^{2}$ & 69 & $\begin{array}{c}89=24 \text { overweight } \\
65 \text { obese }\end{array}$ & \\
\hline
\end{tabular}

Note: ${ }^{a}$ Centers for Disease Control and Prevention (CDC) (2011). Morbidity and Mortality Weekly Report February 4, 2011/60(04), 03-108. 


\section{HTN and CVD Risk Factors}

Population meaningful use HEDIS performance measures from the EMR database were assessed to compare outcomes and other risk factors for CVD. Table 2 shows all clinical measures and their changes between pre-QI measurement $(N=1,210)$ and during the six months of the QI $(N=1,409)$. There was no significant difference in BP control, LDL cholesterol control, BMI, or percentage of patients that used tobacco (Table 2). In this sample, 59\% had a $\mathrm{BP}<140 / 90 \mathrm{mmHg}$ before QI and only $57 \%$ had a BP in that range during QI. For LDL-Cholesterol, $58 \%$ of the sample had $<100 \mathrm{mg} / \mathrm{dL}$ before QI and only $57 \%$ had a similar level during QI. These differences were not significant.

This population had a high rate of tobacco use and of being overweight or obese. Both before and during the QI, $24 \%$ of the sample had a BMI classified as overweight (BMI $>24.9 \mathrm{~kg} / \mathrm{m}^{2}$ but $<30 \mathrm{~kg} / \mathrm{m}^{2}$ ). Obese patients (BMI $>29.9$ $\mathrm{kg} / \mathrm{m}^{2}$ ) made up $65 \%$ of the sample both before and during the QI. Finally, tobacco use amongst patients was the same before and during the QI at 26\%; $78 \%$ were advised to quit before QI, whereas $82 \%$ were advised to quit during QI (Table 2). Table 3 provides a comparison between QI results and the Centers for Disease Control (CDC) US population baseline for the Million Hearts initiative (US Department of Health and Human Services 2011).

\section{Discussion}

This QI initiative began at the start of the national Million Hearts campaign and took a proactive team approach to inform and empower patients who had essential HTN. During the six months of the QI study, the primary goal of having greater than $80 \%$ of HTN patients with documented selfmanagement goals was achieved and was significantly improved from baseline. The percent of adults with controlled HTN did not significantly change. The post-intervention controlled BP $(<140 / 90 \mathrm{mmHg})$ for this patient population was only $57 \%$, better than the nation's population baseline (46\%), but short of the Million Hearts goal of $70 \%$ in the clinic setting and the current HEDIS recommendations of $65 \%$.

As noted in the results, tobacco prevalence was high in this population (26\%) compared to the national level of $20 \%$ (Table 3). A favorable finding of this study was that patients were advised to quit: $78 \%$ were advised to quit before QI, whereas $82 \%$ were advised to quit during QI, much better than the national average of $23 \%$ (Table 3). Advising and assisting patients to quit, along with regulation of tobacco policies and funding for quit lines, could help decrease the prevalence of tobacco use in this population. Studies have shown taxing and increasing the cost of cigarettes decreases tobacco use, especially teenager use and initiation. North Carolina has the $7^{\text {th }}$ lowest US excise sales tax on one pack of cigarettes, which does not discourage smoking. The NC House Bill 2, however, was implemented in 2010, requiring enclosed areas of most restaurants and bars to be smoke-free and providing local governments 
authority to add restrictions or prohibit smoking in public places (American Lung Association 2011).

A surprising result was that $89 \%$ of this population was classified by their BMI as overweight or obese, higher than the national average of $69 \%$ (Table 2). The 2010 North Carolina obesity prevalence was $27.8 \%$; $65 \%$ of the population with HTN in this study was obese. Studies have shown there is a $40 \%$ increased risk of death from CVD for every $5 \mathrm{~kg} / \mathrm{m}^{2}$ increase in BMI above 25kg/m (Centers for Disease Control and Prevention 2011, Prospective Studies Collaboration et al. 2009). Therefore, the majority of our sample has this risk, and weight loss must become a priority in their disease management.

Artinian et al. (2010), in their systematic review for the American Heart Association's (AHA) Scientific Statement on interventions for promoting dietary and physical activity change to reduce CVD risk graded and recommended cognitive-behavioral strategies. Class I (evidence A) included focusing on changing how an individual thinks about themselves, using goal setting, self-monitoring, frequent and prolonged contact, feedback and reinforcement, and self-efficacy enhancement-all of which this QI initiative set out to accomplish. Patients surveyed in the clinic noted the educational brochures, staff support, and community programs were informative and important in setting their goals.

Further, Artinian's systematic review found that group-based interventions, characterized by opportunities for social interaction and support, resulted in better outcomes than individual-based interventions in increased physical activity, dietary changes, and metabolic/vascular biomarkers in both white and minority populations. Participants in the six-week Living Healthy with Chronic Disease class that occurred during this QI project reported the class information, social interaction and support were helpful in achieving their goals in healthy eating, increased physical activity, weight loss, and stress reduction.

The AHA recommends community-based group interventions that are culturally and literacy-level sensitive with assessment of barriers for lowincome populations, along with research studies focused on the impact of community design, affordable healthy foods, and safe environment for exercise related to CVD (Ritchey et al. 2014). Literacy training was done with staff prior to the start and during the QI initiative. The community subgroup of Healthy Carolinians has been instrumental in a heart-smart food-labeling program in the community's grocery stores and healthy suggestions when eating out and at fast-food restaurants. Community assets such as gardens, farmers markets, and walking tracks were promoted in the practice site's community resource guides. Community group classes on healthy living were offered to this population. Because of positive feedback from the Living Healthy with Chronic Disease group, a recommendation was made that this practice site include group classes on HTN at the point of care.

Although self-management goals set did improve in patients with $\mathrm{BP}>139 / 89 \mathrm{mmHg}$ during this QI project, a limitation of this study was its length; it examined only six months of population data prior to the SMS 
intervention and six months during intervention. Nurse-led interventions, medications, and behavior-change programs using motivational techniques for weight loss, use of the DASH diet, increased physical activity, tobacco cessation, and limiting alcohol intake can reduce BP over time (US Department of Health and Human Services 2011, Ritchey et al. 2014, Chobanian et al. 2003, Clark et al. 2010). There may not have been sufficient time for a change in related CVD outcomes between when goals were set and the conclusion of the study. Additionally, this QI intervention may have been hampered by seasonal effects of decreased outdoor physical activity and increased holiday eating during the time period of September 15 to March 14. Also, noted in the review of interventions targeting dietary patterns, weight reduction and new physical activity were variables that "often resulted in impressive rates of initial behavioral changes, but frequently, are not translated into long-term behavioral maintenance" (Artinian et al. 2010). Longitudinal studies are needed to show long-term sustainability as beneficial effects of BP control accrue over time.

Costs effectiveness of this QI project is difficult to assess, as costs are not limited to hospitalization for major CVD events. One in 2.15 patients (18-75 years old) at this primary care practice had the diagnosis of essential HTN. Over $40 \%$ of primary care office visits are related to HTN management in patients 60 years and older (Centers for Disease Control and Prevention 2011). As our nation ages, the economic burden of health care will grow. The treatment of heart disease and stoke accounts for about $\$ 1$ of every $\$ 6.00$ spent on national health care (Johnson 2011). It is estimated that if prevention recommended goals were implemented, this would prevent $2 / 3$ of heart attacks and $1 / 3$ of strokes in the US and save billions of dollars in medical costs.

\section{Clinical Implications}

Current guidelines stress the importance of self-management support. Selfmanagement support is also a key meaningful use measure for implementing a client/patient center medical home. The difficulty is how to address this meaningfully in a brief patient visit. Starting the Conversation brochures and other patient self-management techniques used in this study may prove to be helpful and efficient in a busy clinical setting. Start with Your Heart prescriptions were printed by the NC Department of Health and Human Services at a cost of $\$ 0.82$ cents each (NC Department of Health and Human Services 2012). In this QI study, these materials helped in starting the conversation around goal setting and lifestyle changes, without slowing down the office flow.

As our nation begins to track population meaningful use data, clinicians will need a framework to use AHA's Class I (evidence A) recommendations and prospectively track and evaluate the cost-effectiveness/benefits of various long-term HTN control methodologies (Ritchey et al. 2014). This study is a first step toward using goal setting and SMS for possible improved CVD 
outcomes in a population with significant risk factors such as obesity, tobacco use, and uncontrolled HTN to meet the national Million Heart's ABCS goals.

Client/patient-centered medical homes should use the Chronic Care Model and evidence based guidelines to reduce CVD by:

- making SMS goal setting a part of every patient's office visit and included in the EMR;

- providing group and community supported activities;

- supporting policies and providing resources for safe exercise environments and healthy food options;

- advocating and endorsing tobacco policies and funding that decrease teenage and adult tobacco use, providing both tobacco prevention and cessation programs;

- and providing patient assistance with medications as needed.

By implementing these strategies then prospectively monitoring for improvements in the ABCS and weight reduction, our nation should achieve the Million Hearts goal.

\section{References}

Agency for Healthcare Research and Quality - AHRQ (2012) Self-Management Innovations. Retrievded from http://goo.gl/NB9sFp. [Accessed: 1 June 2012]

American Lung Association (2011) State of Tobacco Control 2010. Retrieved from http://goo.gl/bZIUyM. [Accessed: 1 June 2012].

Artinian NT, Fletcher GF, Mozaffarian D, Kris-Etherton P, Van Horn L, Lichtenstein AH, Kumanyika S, Kraus WE et al. (2010) Interventions to Promote Physical Activity and Dietary Lifestyle Changes for Cardiovascular Risk Factor Reduction in Adults: A Scientific Statement from the American Heart Association. Circulation 122(4): 406-441.

Battersby M, Von Korff M, Schaefer J, Davis C, Ludman E, Greene SM, Parkerton M, Wagner EH (2010) Twelve evidence-based principles for implementing selfmanagement support in primary care. The Joint Commission Journal on Quality and Patient Safety 36(12): 561-570.

Centers for Disease Control and Prevention - CDC (2011) Vital signs: Prevalence, treatment, and control of hypertension-United States, 1999-2002 and 2005-2008. Morbidity and Mortality Weekly Report 60(4): 103-108.

Centers for Disease Control and Prevention, Office of Surveillance, Epidemiology, and Laboratory Services (2012) Behavioral Risk Factor Surveillance System, Prevalence and Trends Data, North Carolina-2011 Hypertension Awareness. Retrieved from http://goo.gl/OfC3OT. [Accessed: 1 June 2012]

Chobanian AV, Bakris GL, Black HR, Cushman WC, Green LA, Izzo JL Jr, Jones DW, Materson BJ et al. (2003) The seventh report of the joint national committee on prevention, detection, evaluation and treatment of high blood pressure: The JNC 7 report. JAMA 289: 2560-2572. 
Clark CE, Smith LF, Taylor RS, Campbell JL (2010) Nurse led interventions to improve control of blood pressure in people with hypertension: Systematic review and meta-analysis. BMJ 341: c3995. [doi: 10.1136/bmj.c3995]

Coleman K, Austin BT, Brach C, Wagner EH (2009) Evidence on the chronic care model in the New Millennium. Health Affairs 28(1): 75-85.

Community Preventive Services Task Force (2012) Guide to Community Preventive Services, Cardiovascular Disease Prevention and Control: Team-Based Care to Improve Blood Pressure Control. Retrieved from http://goo.gl/CYp9BU. [Accessed: 1 June 2012]

Eckel RH, Jakicic JM, Ard JD, de Jesus JM, Miller NH, Hubbard VS, Lee I-M, Lichtenstein AH (2014) AHA/ACC Guideline on lifestyle management to reduce cardiovascular risk: A report of the American College of Cardiology/American Heart Association Task Force on practice guidelines. Journal of the American College of Cardiology 64(25_PA). [doi:10.1016/j.jacc.2013.11.003]

James PA, Oparil S, Carter BL, Cushman WC, Dennison-Himmelfarb C, Handler J, Lackland DT, LeFevre ML (2014) 2014 evidence-based guideline for the management of high blood pressure in adults: Report from the panel members appointed to the eighth joint national committee (JNC 8). JAMA. 311(5): 507520.

Johnson TD (2011) Plan aims to prevent 1 million heart attacks, strokes: HHS, partners seek to reduce rate of cardiovascular disease. The Nation's Health. 41(9): 6.

Lorig K, Holman H, Sobel D (2006) Living a Healthy Life with Chronic Conditions: Self-Management of Heart Disease, Arthritis, Diabetes, Asthma, Bronchitis, Emphysema \& Others. Stanford, CA: Stanford University.

Neal B, MacMahon S, Chapman N (2000) Blood pressure lowering treatment trialists' collaboration. Effects of ACE inhibitors, calcium antagonists, and other bloodpressure-lowering drugs: results of prospectively designed overviews of randomised trials. Lancet 356(9246): 1955-1964.

NC Department of Health and Human Services (2011). Start with Your Heart Prescription for Better Health Raleigh, NC: NC Department of Health and Human Services.

NC Department of Health and Human Services (2012) Start with Your Heart prescriptions. Raleigh, NC: NC Department of Health and Human Services.

NC Prevention Partners (2011) Starting the Conversation on Blood Pressure. Chapel Hill, NC: NC Prevention Partners.

NC State Center for Health Statistics, Division of Public Health (2011) County Health Databook. Retrieved from http://goo.gl/ZiM5wg. [Accessed: 1 June 2012]

Pentecost G (January 7, 2012) Hypertension project aims at reducing occurrences of deaths from heart disease, stroke. The Courier Times.

Prospective Studies Collaboration, Whitlock G, Lewington S, Sherliker P, Clarke R, Emberson J, Halsey J, Qizilbash N (2009) Prospective Studies Collaboration: Body-mass index and cause-specific mortality in 900,000 adults: Collaborative analyses of 57 prospective studies. Lancet 373(9669): 1083-1096.

Ritchey MD, Wall HK, Gillespie C, George MG, Jamal A (2014) Million hearts: Prevalence of leading cardiovascular disease risk factors - United States, 20052012. Morbidity and Mortality Weekly Report 63(21): 462-467.

Tomaselli G, Harty M-B, Horton K, Schoeberl M (2011) The American Heart Association and the Million Hearts Initiative. Circulation 124(16): 1795-1799. 
Turpin R, Jungkind K, Salvucci L (2003) The HEDIS performance NAVIGATOR for controlling high blood pressure: A resource to assist health plans improve patient adherence. Disease Management 6(1): 43-51.

US Bureau of the Census (2011) US Economics and Statistics Administration. Statistical abstract of the United States (130th edn.). Washington, DC: US Census Bureau. Retrieved from http://goo.gl/X0nRxV. [Accessed: 1 June 2012]

US Department of Health and Human Services - HHS (2011) Million Hearts Retrieved from http://goo.gl/QeOzNB. [Accessed: 1 June 2012]

Wright WL, Romboli JE, DiTulio MA, Wogen J, Belletti DA (2011) Hypertension treatment and control within an independent nurse practitioner setting. American Journal of Managed Care 17(1): 58-65. 